\title{
Maternal thyroid disease in the Danish National Birth Cohort: prevalence and risk factors
}

\author{
Stine Linding Andersen ${ }^{1,2}$, Jørn Olsen ${ }^{3}$ and Peter Laurberg ${ }^{1,4}$ \\ Departments of ${ }^{1}$ Endocrinology, ${ }^{2}$ Clinical Biochemistry, Aalborg University Hospital, Sdr. Skovvej 15, 9000 Aalborg, \\ Denmark ${ }^{3}$ Department of Clinical Epidemiology, Aarhus University Hospital, 8000 Aarhus, Denmark and \\ ${ }^{4}$ Department of Clinical Medicine, Aalborg University, 9000 Aalborg, Denmark
}

Correspondence should be addressed to $S \mathrm{~L}$ Andersen Email stine.a@rn.dk

\begin{abstract}
Objective: Thyroid disorders are common in women of reproductive age, but the exact burden of disease before, during and after a pregnancy is not clear. We describe the prevalence of thyroid disease in women enrolled in the Danish National Birth Cohort (DNBC) and investigate some of its risk factors.

Design: Population-based study within the DNBC, which included 101032 pregnancies (1997-2003).

Methods: We studied women enrolled in the DNBC who gave birth to a live-born child. Information on maternal thyroid disease (hyperthyroidism, hypothyroidism, benign goiter/nodules, thyroid cancer, and other) before, during and up to 5 years after the woman's first pregnancy in the cohort was obtained from self-report (telephone interview in median gestational week 17) and from nationwide registers on hospital diagnosis of thyroid disease/thyroid surgery (from 1977) and prescriptions of thyroid drugs (from 1995).

Results: Of the 77445 women studied, 3018 (3.9\%) were identified with an onset of thyroid disease before (2.0\%), during $(0.1 \%)$ or in the 5 -year period after the pregnancy (1.8\%). During the pregnancy, $153(0.2 \%)$ women received antithyroid drugs and $365(0.5 \%)$ received thyroid hormone for hypothyroidism ( 83 after previous hyperthyroidism, 42 after previous surgery for benign goiter/nodules or thyroid cancer). Significant risk factors for maternal thyroid disease were age, parity, origin, iodine intake, smoking, alcohol, and BMI.

Conclusions: Around 4\% of Danish pregnant women had either a history of thyroid disease or thyroid disease during pregnancy or were diagnosed with thyroid disease for the first-time in the years following a pregnancy. The spectrum of thyroid disease was influenced by demographic and environmental factors.

\section{Introduction}

Maternal thyroid dysfunction during a pregnancy has been associated with adverse pregnancy outcomes and impaired child neurocognitive development including low child IQ $(1,2)$ and may even 'program' the fetus to later development of disease (3). The potential benefits and harms of screening for thyroid dysfunction in pregnant women is an ongoing discussion (4). In general, the positive predictive value of a screening test, that is, the probability that subjects with a positive test truly have the disease, depends on the prevalence of the disease in the population being screened (5). Thyroid disorders are considered common in women of reproductive age and are among the major endocrine disorders during pregnancy, but the exact burden of disease before, during and after a pregnancy in a population is not clarified in detail. We describe the prevalence and type of thyroid disease in pregnant women who were enrolled in the Danish National Birth Cohort (DNBC) (6) and gave birth to a live-born child in the years 1997-2003. The development of thyroid disease is influenced by environmental factors, e.g. iodine intake, smoking habits, and alcohol intake (7). Because the frequency of these and other potential risk factors may differ between populations, it is important to recognize and consider such information when comparing

Published by Bioscientifica Ltd. 
the prevalence and type of thyroid disease among populations. We investigate and describe risk factors for maternal thyroid disease in and around pregnancy in the DNBC.

\section{Subjects and methods}

\section{Study population and design}

The DNBC was established in 1996 and aimed to recruit 100000 pregnant women in early pregnancy (6). Enrollment was nationwide and took place at the first antenatal visit to general practice (GP). To be eligible for inclusion, the pregnant women had to live in Denmark, speak Danish well enough to take part in a telephone interview and intend to carry their pregnancy to term. About $50 \%$ of Danish pregnant women received an invitation from their general practitioner to participate and $60 \%$ of the women invited agreed to participate after providing informed consent (6). The women enrolled were asked to fill out a registration form at the time of the first antenatal visit to GP including information on medications used during the pregnancy. In addition to this, they agreed to participate in a 10-30 min telephone interview in early pregnancy, which particularly focused on exposures during the pregnancy. The DNBC enrolled pregnant women who had their antenatal visit to GP in the years 1996-2002 and gave birth in the years 1997-2003 (Fig. 1). All women included in the present study completed the telephone interview in early pregnancy and gave birth to a singleton live-born child (Fig. 2). For women with more than one pregnancy during DNBC study period, only the first pregnancy was included. For all women, information was available on the date of the telephone interview in early pregnancy and on the date the pregnancy was terminated with live-birth. Information on gestational age at birth of the child was obtained from the Danish Medical Birth Registry (MBR) (8) or from the Danish National Hospital Register (DNHR) (9). If no registration was found, gestational age at birth was estimated from the self-reported gestational age at the time of the telephone interview in early pregnancy and the date of pregnancy termination. Pregnancy start (the first day of the last menstrual period) was estimated by subtracting gestational age at birth from the date the child was born.

\section{Information on maternal thyroid disease}

All Danish citizens are provided a unique ten-digit personal identification number that is used in all of the nationwide registers and enables linkage between different registers (10). All data were linked in Statistic Denmark and made available only in encrypted form so that no individuals could be identified by the researcher. Information on maternal thyroid disease included self-reported use of thyroid medication on the registration form completed at the first antenatal visit to GP (median gestational week 8), self-reported thyroid disease and current use of thyroid medication in the telephone interview (median gestational week 17), redeemed prescription of thyroid medication registered in the Danish National Prescription Register (DNPR) (11) from 1995 to 2008 (Fig. 1) and classified according to the Anatomical Therapeutic Chemical (ATC) classification

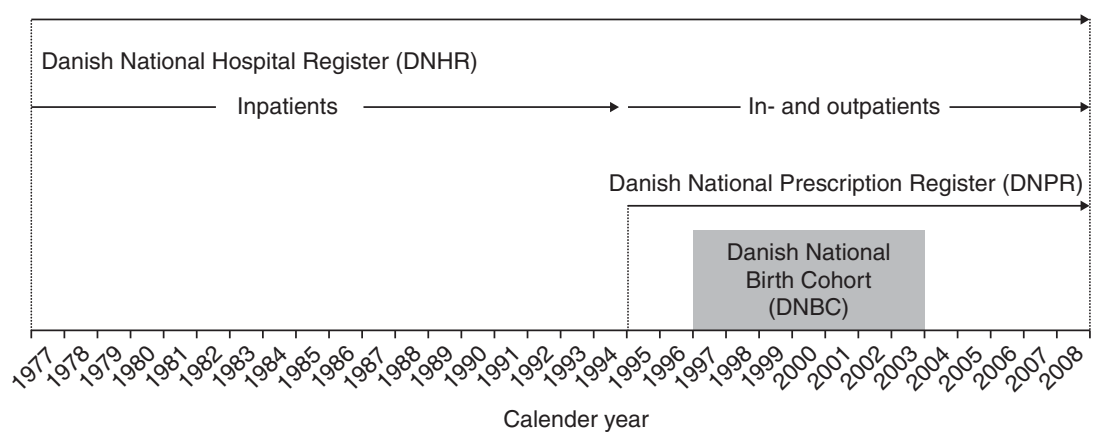

\section{Figure 1}

Illustration of the time period of inclusion in the Danish National Birth Cohort (DNBC) and the nationwide registers. The DNBC included Danish pregnant women giving birth to a live-born child in the years 1997-2003. Information on maternal thyroid disease was obtained from the Danish National Hospital Register (DNHR), which was initiated in 1977 and included both in- and outpatient visits from 1995, and the Danish National Prescription Register (DNPR), which was initiated in 1995. 


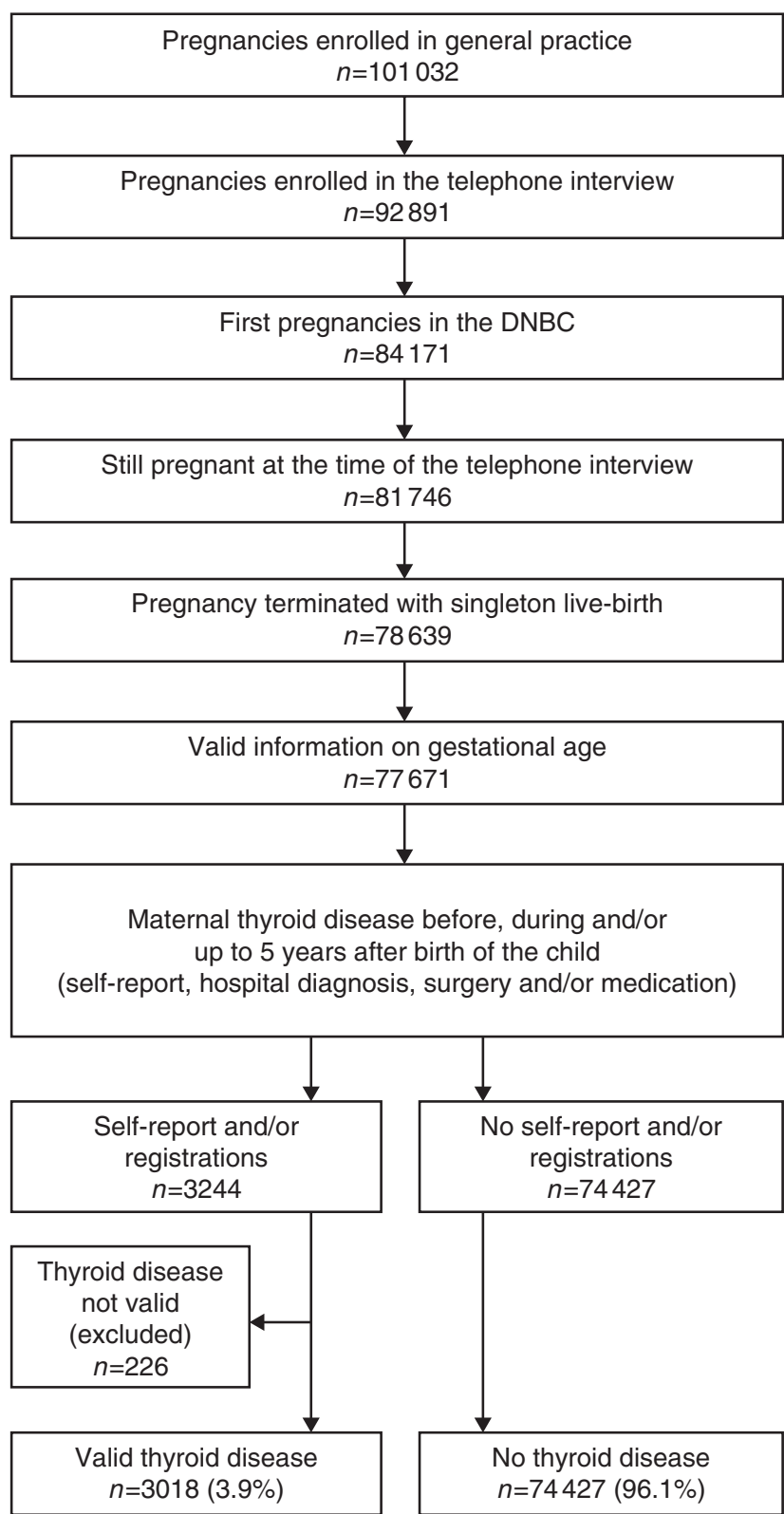

Figure 2

Flowchart illustrating the selection of the pregnant women enrolled in the Danish National Birth Cohort (DNBC) and included in the present study.

system (thyroid hormone: ATC H03A and antithyroid drug (ATD): H03B) and hospital diagnosis of thyroid disease and surgery registered in the DNHR from 1977 to 2008 (Fig. 1). The DNHR (9) holds data on all inpatient visits to any Danish hospital since 1977 and all in- and out-patient visits since 1995. The diagnoses were classified according to the 8 th revision of the International Classification of Disease (ICD8) from 1977 to 1993 and the 10th revision (ICD10) from 1994. We included information on all in- and out-patient visits with thyroid disease using ICD8 (193.99 and 240.09-246.09) and ICD10 codes (C73.9, E00.0-E07.9, E89.0, O90.5). Thyroid surgery was defined by ICD8: 080.60-082.20 and ICD10: BAA20-BAA60.

\section{Onset of maternal thyroid disease}

For each of the women included, information on maternal thyroid disease was obtained before, during and up to 5 years after the termination of the pregnancy (Fig. 2). Of the women with self-reported information on thyroid disease, an individual review of interviews revealed that 226 women (Fig. 2) did not report valid thyroid disease (the disease reported was unlikely to be thyroid disease; $n=104)$ or reported 'do not know' ( $n=58)$, 'thyroid disease not verified by a doctor' $(n=62)$, or thyroid medication on the registration form alone $(n=2)$.

Women were classified with onset of thyroid disease before the telephone interview in early pregnancy if they reported previous or current thyroid disease in the interview or had previous registrations of thyroid disease. In these women, onset of thyroid disease in pregnancy was specified if the first registration of thyroid disease was in the period ranging from the estimated pregnancy start to the date of the interview. Women were classified with onset of thyroid disease after the telephone interview if they did not report current or previous thyroid disease in the interview and had the first registration of thyroid disease after the interview. An exception from this was women $(n=5)$ who had previous registrations of thyroid disease but were first time diagnosed and treated for thyroid cancer after the pregnancy. These women were classified with onset of thyroid cancer after the pregnancy.

Women identified with thyroid disease before or during the pregnancy were followed from the onset of disease to evaluate if the disease was treated during the pregnancy. Treatment with ATD and/or thyroid hormone in the pregnancy was defined by redeemed prescription(s) in the period ranging from 6 months before the estimated pregnancy start to the date of pregnancy termination.

\section{Type of maternal thyroid disease}

For women with onset of thyroid disease before the telephone interview during pregnancy, the type of thyroid disease was classified according to self-report and registrations prior to the interview, and for women with onset of thyroid disease after the interview, the type of thyroid 
disease was classified according to registrations in late pregnancy or in the 5-year period after the pregnancy. First, maternal thyroid disease was classified as thyroid cancer if the woman had a minimum of two hospital diagnoses of thyroid cancer and also had a diagnosis of thyroid cancer after thyroid surgery had been performed. Second, maternal hyperthyroidism was defined as redeemed prescription(s) of ATD and/or hospital diagnosis of hyperthyroidism and/or self-reported hyperthyroidism. Among the remaining women, maternal hypothyroidism was defined as redeemed prescription(s) of thyroid hormone and/or hospital diagnosis of hypothyroidism and/or self-reported hypothyroidism. Hypothyroidism was classified as non-surgical (no registration of thyroid surgery) or surgical (registration of thyroid surgery). Women with surgical hypothyroidism were classified as benign thyroid goiter/nodules as were women with a hospital diagnosis of benign thyroid goiter/nodules and/or self-reported benign thyroid goiter/nodules and/or thyroid surgery. Finally, a small group of women had only a hospital diagnosis/self-report of unspecified thyroid disease or thyroiditis and were classified in the subtype group 'other'.

\section{Information on risk factors}

Information on maternal characteristics at birth of the child was obtained from the MBR (age and parity) and from Statistic Denmark (origin and geographical residence). Geographical residence was used as an instrumental variable for iodine intake. Denmark was previously iodine deficient (ID) with regional differences due to diverse content of iodine in drinking water (12). Divided by the Great Belt, the population suffered from moderate ID in West Denmark and mild ID in East Denmark. A mandatory iodine fortification of salt was introduced in the year 2000 . Information on maternal smoking during pregnancy, pre-pregnancy alcohol intake (units of beer, wine, and spirits per week) and pre-pregnancy height and weight was self-reported in the pregnancy telephone interview.

\section{Statistical analyses}

Women with information on thyroid disease considered non-valid were excluded from the study (Fig. 2), leaving 77445 women as the final study population. The prevalence of thyroid disease was estimated as the percentages of all within the study population and stratified according to the time of disease onset and type of thyroid disease. Risk factors for maternal thyroid disease were investigated in univariate stratified analyses and in a multivariate logistic regression model including age, parity, iodine intake, smoking, alcohol intake, BMI, and origin as dichotomous explanatory variables. Outcome variables were hyperthyroidism, hypothyroidism and benign goiter/nodules in separate models, and the reference group was women with no thyroid disease up to 5 years after the pregnancy ( $n=74427$ ). The number of women identified with thyroid cancer was too small to perform multivariate analyses for this type of thyroid disease.

Statistical analyses were performed using STATA version 11 (Stata Corp., College Station, TX, USA) and a $5 \%$ level of significance was chosen. The study was approved by the Danish Data Protection Agency.

Table 1 Prevalences of thyroid disease among 77445 pregnant women enrolled in the Danish National Birth Cohort (DNBC) from 1997 to 2003 stratified by time of disease onset and type of thyroid disease.

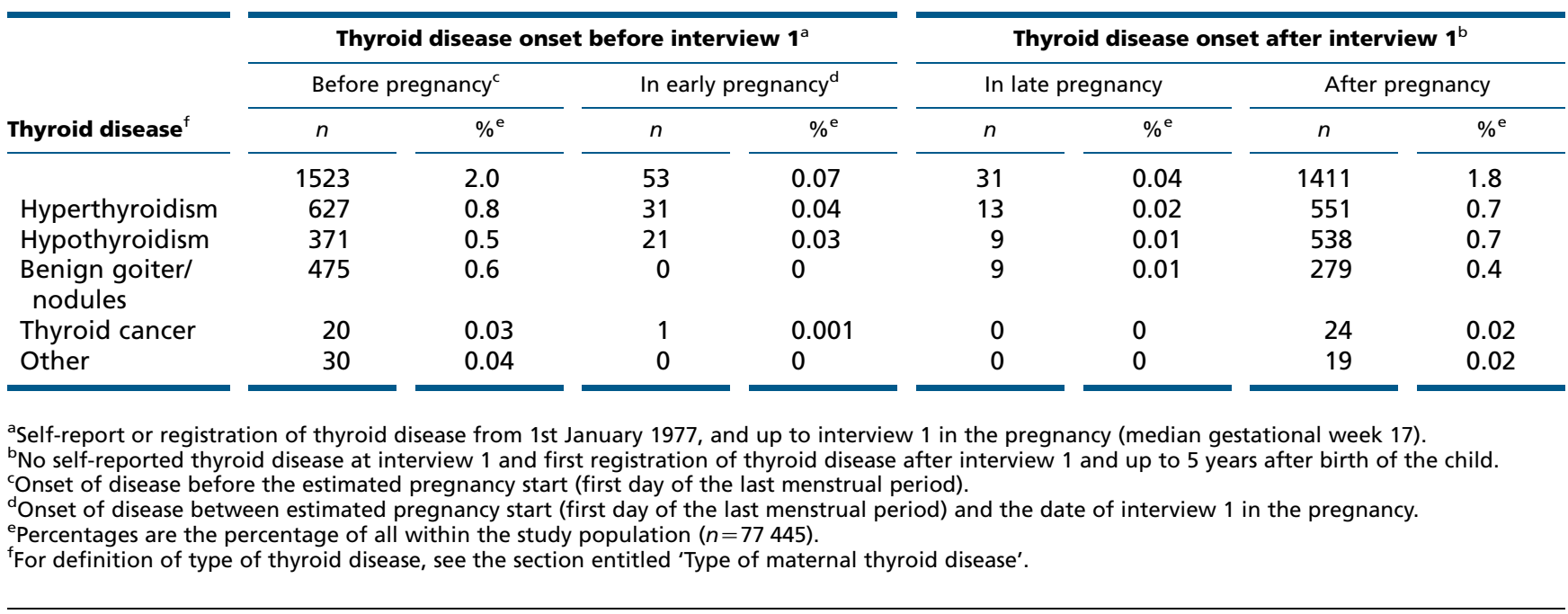




\section{Results}

\section{Prevalence of maternal thyroid disease}

A total of 3018 women (3.9\%) had thyroid disease before, during or up to 5 years after the pregnancy (Fig. 2) and were classified according to onset of disease and type of thyroid disease (Table 1). In general, the number of women with onset of disease before and in the 5-year period after the pregnancy was almost equal (1.8-2.0\%), whereas onset of disease in the pregnancy was rare $(0.1 \%)$ (Table 1). Hyperthyroidism was the most prevalent type of thyroid disease $(n=1222 ; 1.6 \%)$, followed by hypothyroidism $(n=939 ; 1.2 \%)$ and benign goiter/nodules $(n=763 ; 1.0 \%)$, whereas thyroid cancer was rare $(n=45)$.

Women with onset of disease before or during the pregnancy $(n=1577)$ were followed up to ascertain if they received treatment for the disease during the pregnancy under study (Table 2). Altogether 153 women $(0.2 \%)$ were treated with ATD for hyperthyroidism during pregnancy and 365 (0.5\%) were treated with thyroid hormone for hypothyroidism during pregnancy, of whom 83 had hypothyroidism after previous hyperthyroidism and 42 after previous surgery for nodular disease. Three women (Table 2) underwent thyroid surgery during pregnancy for hyperthyroidism, benign goiter and thyroid cancer respectively. Of the women identified with onset of thyroid disease during pregnancy (Table 2), a group of women had a hospital diagnosis of the disease, but no registration of medical or surgical treatment during the pregnancy was available (hyperthyroidism, $n=20$; hypothyroidism, $n=6$; and benign goiter/nodules, $n=9$ ). These women most likely suffered from borderline thyroid abnormalities in the pregnancy that ameliorated during the pregnancy with no need for treatment. However, some of these women had treatment initiated in the 5 -year period after birth of the child (hyperthyroidism, $n=6$; hypothyroidism, $n=4$; and benign goiter/nodules, $n=5$ ).

\section{Risk factors for maternal thyroid disease}

Risk factors for the three most common types of thyroid disease (hyperthyroidism, non-surgical hypothyroidism, and benign goiter/nodules) were investigated in univariate (Table 3) and multivariate analyses (Fig. 3). In general, women with thyroid disease were older with a higher parity (Table 3). The correlation with age was also pronounced in the multivariate analyses, whereas a significant relationship to parity was observed for benign goiter/nodules only (Fig. 3). Hypothyroidism was more frequent in East Denmark with only mild ID, whereas hyperthyroidism and benign goiter/nodules were more frequent in West Denmark with moderate ID. Smoking during pregnancy was associated with an increased risk of hyperthyroidism and benign goiter/nodules and a decreased risk of hypothyroidism. On the other hand, pre-pregnancy alcohol intake significantly correlated with a low prevalence of hyperthyroidism and also tended to

Table 2 Type of thyroid disease and treatment in the pregnancy among 1577 women identified with onset of thyroid disease before or during the pregnancy under study.

\begin{tabular}{|c|c|c|c|c|}
\hline & Hyperthyroidism $(n)^{a}$ & Hypothyroidism $(n)^{\mathrm{a}}$ & Benign goiter/nodules $(n)^{\mathrm{a}}$ & Thyroid cancer $(n)^{\mathrm{a}}$ \\
\hline Onset before the pregnancy & 627 & 371 & 475 & 20 \\
\hline No treatment in the pregnancy ${ }^{b}$ & 414 & 155 & 453 & 0 \\
\hline Treatment in the pregnancy ${ }^{\mathrm{c}}$ & 213 & 216 & 22 & 20 \\
\hline Antithyroid drug (ATD) ${ }^{\mathrm{d}}$ & 129 & 0 & 0 & 0 \\
\hline Thyroid hormone $\mathrm{e}^{\mathrm{e}}$ & 83 & 216 & 21 & 20 \\
\hline Surgery ${ }^{f}$ & 1 & 0 & 1 & 0 \\
\hline Onset in the pregnancy & 44 & 30 & 9 & 1 \\
\hline No treatment in the pregnancy ${ }^{b}$ & 20 & 6 & 9 & 0 \\
\hline Treatment in the pregnancy ${ }^{\mathrm{c}}$ & 24 & 24 & 0 & 1 \\
\hline ATD $^{d}$ & 24 & 0 & 0 & 0 \\
\hline Thyroid hormone $\mathrm{e}^{\mathrm{e}}$ & 0 & 24 & 0 & 0 \\
\hline Surgery ${ }^{g}$ & 0 & 0 & 0 & 1 \\
\hline
\end{tabular}

${ }^{a}$ For definition of type of thyroid disease, see the method section 'Type of maternal thyroid disease' and Table 1 . Women with onset of thyroid disease 'other' $(n=30)$ before the pregnancy were not included.

${ }^{b}$ No redeemed prescription of ATD or thyroid hormone and no thyroid surgery in the period from 6 months before pregnancy to birth of the child.

${ }^{c}$ Redeemed prescription of ATD and/or thyroid hormone and/or thyroid surgery in the period from 6 months before pregnancy to birth of the child.

${ }^{\mathrm{d}}$ Redeemed prescription of ATD +/-thyroid hormone, no registration of thyroid surgery.

${ }^{e}$ Redeemed prescription of thyroid hormone, no redeemed prescription of ATD and no registration of thyroid surgery.

${ }^{f}$ Registration of thyroid surgery, no redeemed prescription of ATD or thyroid hormone.

${ }^{\mathrm{g}}$ Registration of thyroid surgery and redeemed prescriptions of thyroid hormone. 
Table 3 Characteristics of pregnant women enrolled in the Danish National Birth Cohort (DNBC) and giving birth to a live-born child from 1997 to 2003 according to type of thyroid disease.

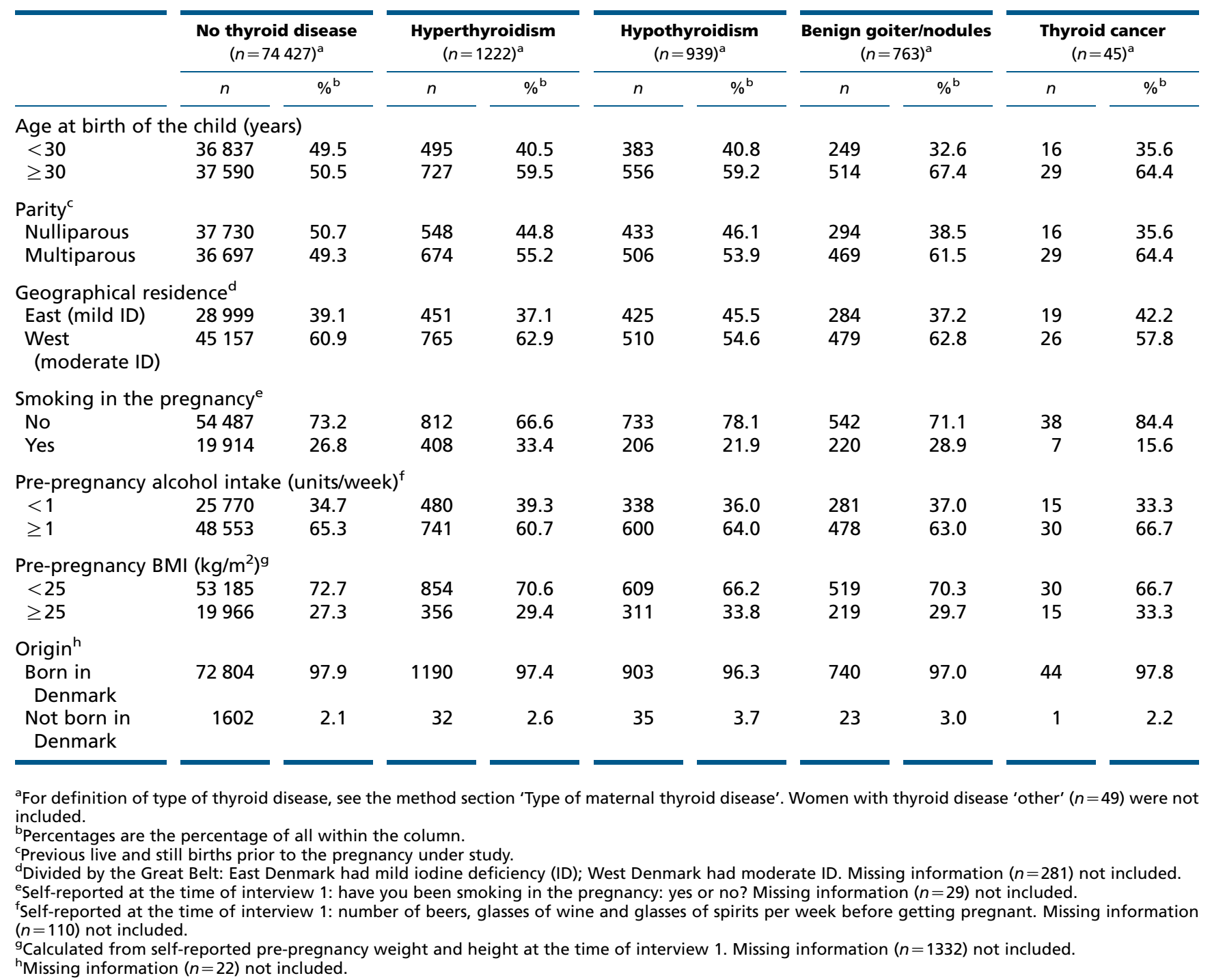

associate with a low prevalence of benign goiter/nodules and hypothyroidism. For the potential protective impact of alcohol on the development of hyperthyroidism, a dose-dependent trend was observed in multivariate analysis ( $<1$ unit/week (reference), 1-7 units/week (OR 0.84 (95\% CI 0.74-0.95)), 8-14 units/week (0.67 (0.52$0.86))$, and $>14$ units/week $(0.42(0.21-0.84)))$. High prepregnancy BMI and maternal origin other than Danish were significant risk factors for hypothyroidism.

Information on previous thyroid disease was mainly based on self-report, and 322 women had only self-reported disease (hyperthyroidism, $n=146$; hypothyroidism, $n=60$; and benign goiter/nodules, $n=16$ ), but the exclusion of this group of women did not change the results of the multivariate analyses. Furthermore, the stratification of analyses according to onset of disease (before/after birth of the child) did not considerably change the associations observed (data not shown).

\section{Discussion}

\section{Principle findings}

In the large DNBC of pregnant women enrolled in the years $1997-2003,4 \%$ of the women had previous or ongoing thyroid disease or developed thyroid disease in or up to 5 years after pregnancy and $0.5-1.0 \%$ were treated for thyroid disease during the pregnancy under study. 


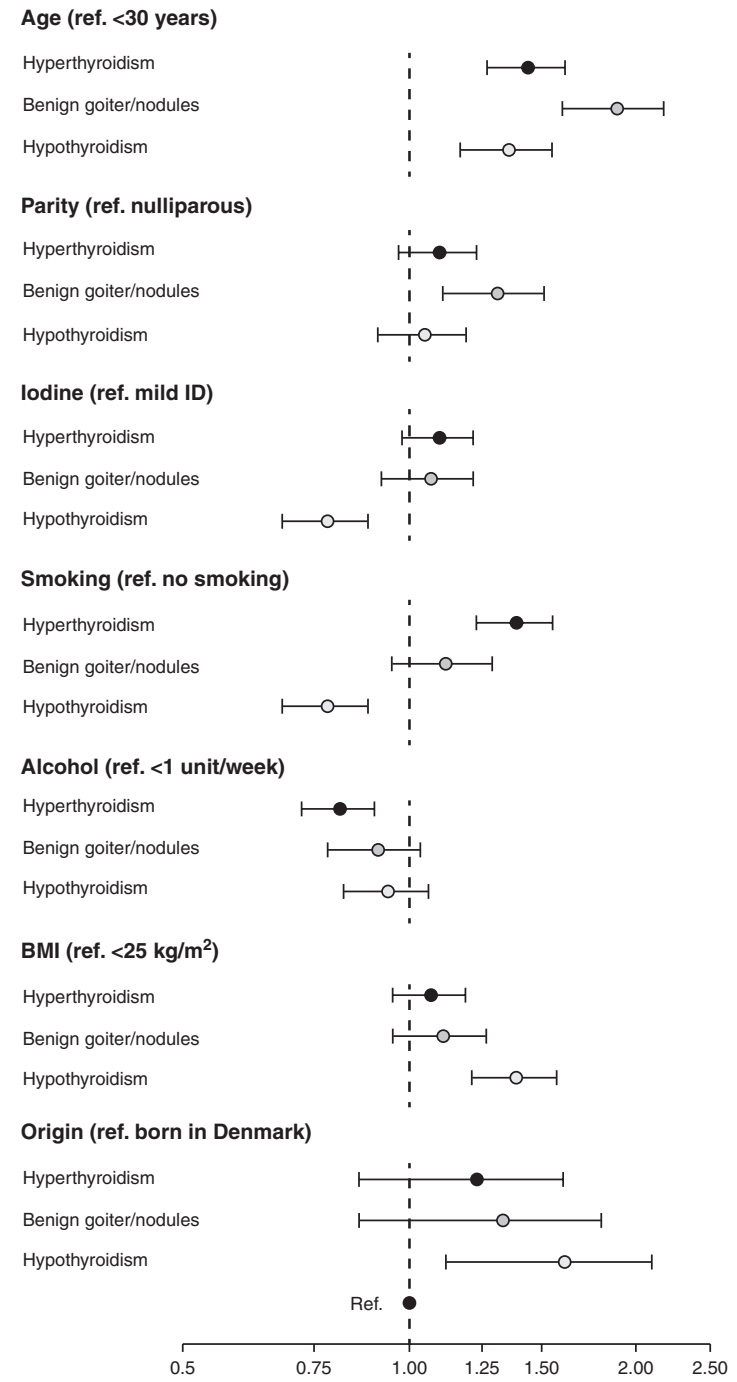

\section{Figure 3}

Multivariate logistic regression analysis of demographic and environmental factors associated with maternal thyroid disease before, during and/or up to 5 years after the pregnancy under study. Analyses were performed separately for each of the dependent variables: hyperthyroidism (black circle), benign goiter/nodules (grey circle), and hypothyroidism (white circle). The model included all explanatory variables illustrated (maternal age ( $\geq 30$ years vs $<30$ years), parity (multiparous vs nulliparous), iodine (living in moderate vs mild iodine deficiency (ID)), smoking in the pregnancy (yes vs no), pre-pregnancy alcohol intake ( $\geq 1$ unit/week vs $<1$ unit/week), pre-pregnancy BMI ( $\geq 25 \mathrm{~kg} / \mathrm{m}^{2}$ vs $<25 \mathrm{~kg} / \mathrm{m}^{2}$ ), and origin (not born in Denmark vs born in Denmark)). The reference group (Ref.) for the dependent variables was the 74427 pregnant women with no self-reported disease or registration of thyroid disease before, during or up to 5 years after the pregnancy. ref., reference.
Demographic and environmental factors including maternal age, parity, origin, iodine intake, smoking, alcohol, and BMI were associated with the development of thyroid disease.

\section{Prevalence of thyroid disease in pregnancy}

The prevalence of thyroid disease in pregnant women will depend on the method and information sources applied as well as the composition of the study population. Thyroid disease in women of reproductive age is predominantly of autoimmune origin $(13,14)$, and it is well established that both genetic and environmental factors may influence the development of disease (7). Thus, when comparing the prevalence of thyroid disease in general and in pregnant women specifically, it is important to consider differences between study populations with regard to demographics and environmental factors.

Published data on the prevalence of thyroid disease in pregnant women have been based on results of thyroid function tests and/or registration of hospital diagnosis and treatment. Studies with biochemical measurement of thyroid function have used stored serum samples collected as a part of routine prenatal programs $(15,16)$, serum samples collected from women enrolled in a pregnancy cohort (17) or serum samples from women enrolled in a randomized trial (18). In such studies, the prevalence of disease depends on the biochemical definition of thyroid disease as well as the gestational week of sampling. Similarly for register-based studies $(19,20,21)$, the prevalence of disease will depend on the criteria applied and the available registered information. We evaluated the prevalence of thyroid dysfunction in the DNBC by redeemed prescription of thyroid medication and observed that $0.2 \%$ of the women were treated for hyperthyroidism and $0.5 \%$ for hypothyroidism in the pregnancy. These findings are in line with the general figures often given on overt thyroid dysfunction in pregnancy that both overt hyperthyroidism and hypothyroidism affect $<1 \%$ of pregnancies $(1,2,22,23,24)$. However, our DNBC data illustrate that prevalences are highly dependent on demographic and environmental factors, which is in line with reports on risk factors for thyroid disease in the general population $(13,14,25,26,27,28)$.

We observed that the development of maternal thyroid disease before, during and in the years following a pregnancy was influenced by a series of factors such as maternal age, parity, origin, iodine intake, BMI, alcohol, and smoking and that the association differed for subtypes of thyroid disease. Further studies are needed to 
corroborate the associations observed, but the changes over time in demographic characteristics of women of childbearing age in many countries (e.g. increasing maternal age at first pregnancy) and in various environmental exposures (e.g. changes in smoking and drinking habits) may potentially change the risk and type of thyroid disease in pregnant women. Notably, increasing maternal age was a risk factor for all types of thyroid disease. Considering environmental factors, maternal pre-pregnancy alcohol intake was associated with a reduced risk of hyperthyroidism and also tended to reduce the risk of hypothyroidism and benign goiter/nodules, whereas maternal smoking in pregnancy increased the risk of hyperthyroidism and decreased the risk of hypothyroidism (29).

Another environmental factor that differs between populations and may change over time is iodine intake. The women were enrolled in the DNBC from 1997 to 2003, which was a period overlapping the introduction of the mandatory iodine fortification of salt (year 2000) in Denmark. We observed that living in West Denmark, an area that was previously considered to be most pronounced with ID (moderate ID) was a risk factor for hyperthyroidism and benign goiter/nodules, whereas hypothyroidism was more common in East Denmark with mild ID comparable with the findings from the general Danish population studies (DanThyr) (12). In mild to moderate ID, the thyroid gland is typically able to keep thyroid hormone synthesis sufficient due to a compensatory increased activity, but this hyperactivity may lead to the development of thyroid autonomy and a higher rate of toxic nodular goiter (30). The introduction of the Danish iodine fortification of salt led to a transient increase in the incidence of hyperthyroidism, which was most pronounced in West Denmark $(31,32)$. This may have contributed to the regional difference observed in the present study.

\section{Methodological comments}

The DNBC was established as a nationwide birth cohort and aimed to cover all regions of Denmark (6). To participate, the women had to speak Danish well enough to participate in the telephone interview, which would under-represent women of other origins. In the present study we only included women according to their first pregnancy in DNBC and only pregnancies terminated with live-birth to ensure that the early pregnancy telephone interview had been performed. Maternal thyroid disease may increase the risk of both early and late pregnancy loss (33), and the inclusion criterion for live-birth in the present study could tend to underestimate the prevalence of maternal thyroid disease.
The present study relied on links to Danish nationwide registers with a high coverage and validity of hospital diagnoses of disease and surgery and redeemed prescriptions of drugs $(9,11)$. However, the period of registration differs for the various registers and information on previous thyroid disease was mainly from self-report because the registration of outpatients and prescriptions was first initiated in 1995. Finally, we had no registered information on radioiodine treatment. We acknowledge that results of the present study were based on registrations of self-reported disease and diagnoses/treatment of thyroid disease, whereas no information on actual measurement of thyroid function tests was available. No systematic screening was performed, thus, the figures presented may not represent the true prevalence of maternal thyroid disease.

\section{Clinical perspective}

Maternal thyroid dysfunction may adversely complicate a pregnancy and may also 'program' the fetus to later development of disease $(3,19,33,34)$. Newly diagnosed thyroid dysfunction during a pregnancy is rare. On the other hand, around $2 \%$ of pregnant women in the DNBC had a history of thyroid disease at the time they became pregnant and another $2 \%$ developed thyroid disease in the 5 -year period following the pregnancy. Women with known thyroid disease prior to a pregnancy may not be adequately treated by the time they become pregnant, and women first time diagnosed and treated for thyroid disease after a pregnancy could have suffered from undetected and untreated thyroid dysfunction during the pregnancy $(35,36,37,38)$. Such potential thyroid abnormalities may adversely affect fetal development, particularly early brain development. Clinicians should be aware of potential thyroid disease in pregnant women. Women with known thyroid disease prior to a pregnancy should be carefully managed and controlled. Even if thyroid dysfunction is not known, the threshold for thyroid function testing in pregnancy should be low.

\section{Declaration of interest}

The authors declare that there is no conflict of interest that could be perceived as prejudicing the impartiality of the research reported.

\section{Funding}

The Danish National Research Foundation has established the Danish Epidemiology Science Centre that initiated and created the DNBC. Furthermore, this cohort is a result of a major grant from this Foundation. 
Additional support for the DNBC is obtained from the Pharmacy Foundation, the Egmont Foundation, the March of Dimes Birth Defects Foundation, the Augustinus Foundation, and the Health Foundation.

\section{References}

1 Cooper DS \& Laurberg P. Hyperthyroidism in pregnancy. Lancet. Diabetes \& Endocrinology 20131 238-249. (doi:10.1016/S22138587(13)70086-X)

2 Teng W, Shan Z, Patil-Sisodia K \& Cooper DS. Hypothyroidism in pregnancy. Lancet. Diabetes \& Endocrinology $20131228-237$. (doi:10.1016/S2213-8587(13)70109-8)

3 Andersen SL, Olsen J \& Laurberg P. Foetal programming by maternal thyroid disease. Clinical Endocrinology 201583 751-758. (doi:10.1111/ cen.12744)

4 Laurberg P, Andersen SL, Pedersen IB, Andersen S \& Carle A. Screening for overt thyroid disease in early pregnancy may be preferable to searching for small aberrations in thyroid function tests. Clinical Endocrinology 201379 297-304. (doi:10.1111/cen.12232)

5 Altman DG \& Bland JM. Diagnostic tests 2: predictive values. BMJ 1994 309 102. (doi:10.1136/bmj.309.6947.102)

6 Olsen J, Melbye M, Olsen SF, Sorensen TI, Aaby P, Andersen AM, Taxbol D, Hansen KD, Juhl M, Schow TB et al. The Danish National Birth Cohort - its background, structure and aim. Scandinavian Journal of Public Health 200129 300-307. (doi:10.1177/ 14034948010290040201)

7 Laurberg P, Andersen S, Pedersen IB, Knudsen N \& Carlé A. Prevention of autoimmune hypothyroidism by modifying iodine intake and the use of tobacco and alcohol is manoeuvring between Scylla and Charybdis. Hormones 201312 29-37.

8 Knudsen LB \& Olsen J. The Danish Medical Birth Registry. Danish Medical Bulletin 199845 320-323.

9 Andersen TF, Madsen M, Jorgensen J, Mellemkjoer L \& Olsen JH. The Danish National Hospital Register. A valuable source of data for modern health sciences. Danish Medical Bulletin 199946 263-268.

10 Pedersen СB. The Danish Civil Registration System. Scandinavian Journal of Public Health 201139 22-25. (doi:10.1177/ 1403494810387965)

11 Kildemoes HW, Sorensen HT \& Hallas J. The Danish National Prescription Registry. Scandinavian Journal of Public Health 201139 38-41. (doi:10.1177/1403494810394717)

12 Laurberg P, Jorgensen T, Perrild H, Ovesen L, Knudsen N, Pedersen IB, Rasmussen LB, Carle A \& Vejbjerg P. The Danish investigation on iodine intake and thyroid disease, DanThyr: status and perspectives. European Journal of Endocrinology 2006155 219-228. (doi:10.1530/eje.1. 02210)

13 Carle A, Laurberg P, Pedersen IB, Knudsen N, Perrild H, Ovesen L, Rasmussen LB \& Jorgensen T. Epidemiology of subtypes of hypothyroidism in Denmark. European Journal of Endocrinology 2006 154 21-28. (doi:10.1530/eje.1.02068)

14 Carle A, Pedersen IB, Knudsen N, Perrild H, Ovesen L, Rasmussen LB \& Laurberg P. Epidemiology of subtypes of hyperthyroidism in Denmark: a population-based study. European Journal of Endocrinology 2011164 801-809. (doi:10.1530/EJE-10-1155)

15 Haddow JE, Palomaki GE, Allan WC, Williams JR, Knight GJ, Gagnon J, O'Heir CE, Mitchell ML, Hermos RJ, Waisbren SE et al. Maternal thyroid deficiency during pregnancy and subsequent neuropsychological development of the child. New England Journal of Medicine $19993 \mathbf{3 4 1}$ 549-555. (doi:10.1056/NEJM199908193410801)

16 Allan WC, Haddow JE, Palomaki GE, Williams JR, Mitchell ML, Hermos RJ, Faix JD \& Klein RZ. Maternal thyroid deficiency and pregnancy complications: implications for population screening. Journal of Medical Screening 20007 127-130. (doi:10.1136/jms.7.3.127)
17 Mannisto T, Vaarasmaki M, Pouta A, Hartikainen AL, Ruokonen A, Surcel HM, Bloigu A, Jarvelin MR \& Suvanto-Luukkonen E. Perinatal outcome of children born to mothers with thyroid dysfunction or antibodies: a prospective population-based cohort study. Journal of Clinical Endocrinology and Metabolism 200994 772-779. (doi:10.1210/ jc.2008-1520)

18 Lazarus JH, Bestwick JP, Channon S, Paradice R, Maina A, Rees R, Chiusano E, John R, Guaraldo V, George LM et al. Antenatal thyroid screening and childhood cognitive function. New England Journal of Medicine 2012366 493-501. (doi:10.1056/NEJMoa1106104)

19 Andersen SL, Olsen J, Wu CS \& Laurberg P. Birth defects after early pregnancy use of antithyroid drugs: a Danish nationwide study. Journal of Clinical Endocrinology and Metabolism 201398 4373-4381. (doi:10.1210/jc.2013-2831)

20 Lo JC, Rivkees SA, Chandra M, Gonzalez JR, Korelitz JJ \& Kuzniewicz MW. Gestational thyrotoxicosis, antithyroid drug use and neonatal outcomes within an integrated healthcare delivery system. Thyroid 201525 698-705. (doi:10.1089/thy.2014.0434)

21 Andersen SL, Olsen J, Carle A \& Laurberg P. Hyperthyroidism incidence fluctuates widely in and around pregnancy and is at variance with some other autoimmune diseases: a Danish population-based study. Journal of Clinical Endocrinology and Metabolism 2015100 1164-1171. (doi:10.1210/jc.2014-3588)

22 De Groot L, Abalovich M, Alexander EK, Amino N, Barbour L, Cobin RH, Eastman CJ, Lazarus JH, Luton D, Mandel SJ et al. Management of thyroid dysfunction during pregnancy and postpartum: an Endocrine Society Clinical Practice Guideline. Journal of Clinical Endocrinology and Metabolism 201297 2543-2565. (doi:10.1210/jc.2011-2803)

23 Bahn RS, Burch HB, Cooper DS, Garber JR, Greenlee MC, Klein I, Laurberg P, McDougall IR, Montori VM, Rivkees SA et al. Hyperthyroidism and other causes of thyrotoxicosis: management guidelines of the American Thyroid Association and American Association of Clinical Endocrinologists. Thyroid 201121 593-646. (doi:10.1089/thy. 2010.0417)

24 Stagnaro-Green A, Abalovich M, Alexander E, Azizi F, Mestman J, Negro R, Nixon A, Pearce EN, Soldin OP, Sullivan S et al. Guidelines of the American Thyroid Association for the diagnosis and management of thyroid disease during pregnancy and postpartum. Thyroid 201121 1081-1125. (doi:10.1089/thy.2011.0087)

25 Carle A, Pedersen IB, Knudsen N, Perrild H, Ovesen L, Rasmussen LB, Jorgensen T \& Laurberg P. Moderate alcohol consumption may protect against overt autoimmune hypothyroidism: a population-based case-control study. European Journal of Endocrinology 2012167 483-490. (doi:10.1530/EJE-12-0356)

26 Carle A, Bulow Pedersen I, Knudsen N, Perrild H, Ovesen L, Banke Rasmussen L, Jorgensen T \& Laurberg P. Smoking cessation is followed by a sharp but transient rise in the incidence of overt autoimmune hypothyroidism - a population-based, case-control study. Clinical Endocrinology 201277 764-772. (doi:10.1111/j.13652265.2012.04455.x)

27 Carle A, Bulow Pedersen I, Knudsen N, Perrild H, Ovesen L, Rasmussen LB, Jorgensen T \& Laurberg P. Graves' hyperthyroidism and moderate alcohol consumption: evidence for disease prevention. Clinical Endocrinology 201379 111-119. (doi:10.1111/cen.12106)

28 Knudsen N. Risk factors for benign thyroid disease. Danish Medical Bulletin 200552 160-185.

29 Andersen SL, Olsen J, Wu CS \& Laurberg P. Smoking reduces the risk of hypothyroidism and increases the risk of hyperthyroidism: evidence from 450,842 mothers giving birth in Denmark. Clinical Endocrinology 201480 307-314. (doi:10.1111/cen.12279)

30 Laurberg P, Cerqueira C, Ovesen L, Rasmussen LB, Perrild H, Andersen S, Pedersen IB \& Carle A. Iodine intake as a determinant of thyroid disorders in populations. Best Practice \& Research. Clinical Endocrinology \& Metabolism 201024 13-27. (doi:10.1016/j.beem.2009.08.013)

31 Bulow Pedersen I, Laurberg P, Knudsen N, Jorgensen T, Perrild H, Ovesen L \& Rasmussen LB. Increase in incidence of hyperthyroidism 
predominantly occurs in young people after iodine fortification of salt in Denmark. Journal of Clinical Endocrinology and Metabolism 200691 3830-3834. (doi:10.1210/jc.2006-0652)

32 Cerqueira C, Knudsen N, Ovesen L, Perrild H, Rasmussen LB, Laurberg P $\&$ Jorgensen T. Association of iodine fortification with incident use of antithyroid medication - a Danish Nationwide Study. Journal of Clinical Endocrinology and Metabolism 200994 2400-2405. (doi:10.1210/jc. 2009-0123)

33 Andersen SL, Olsen J, Wu CS \& Laurberg P. Spontaneous abortion, stillbirth and hyperthyroidism: a Danish population-based study. European Thyroid Journal 20143 164-172. (doi:10.1159/ 000365101)

34 Andersen SL, Olsen J, Wu CS \& Laurberg P. Low birth weight in children born to mothers with hyperthyroidism and high birth weight in hypothyroidism, whereas preterm birth is common in both conditions: a Danish National Hospital Register study. European Thyroid Journal 20132 135-144. (doi:10.1159/000350513)
35 Hallengren B, Lantz M, Andreasson B \& Grennert L. Pregnant women on thyroxine substitution are often dysregulated in early pregnancy. Thyroid 200919 391-394. (doi:10.1089/thy.2008.0206)

36 Granfors M, Akerud H, Berglund A, Skogo J, Sundstrom-Poromaa I \& Wikstrom AK. Thyroid testing and management of hypothyroidism during pregnancy: a population-based study. Journal of Clinical Endocrinology and Metabolism 201398 2687-2692. (doi:10.1210/jc. 2013-1302)

37 Taylor PN, Minassian C, Rehman A, Iqbal A, Draman MS, Hamilton W, Dunlop D, Robinson A, Vaidya B, Lazarus JH et al. TSH levels and risk of miscarriage in women on long-term levothyroxine: a communitybased study. Journal of Clinical Endocrinology and Metabolism 201499 3895-3902. (doi:10.1210/jc.2014-1954)

38 Hubaveshka J, Michaelsson LF \& Nygaard B. The dose of levothyroxine in pregnant women with hypothyroidism should be increased by 20-30\% in the first trimester. Danish Medical Journal 2014 61 A4959.

Received 11 August 2015

Revised version received 2 October 2015

Accepted 18 November 2015 